\title{
PVD-grown antibacterial Ag-TiN films on piezoelectric PVDF substrates for sensor applications
}

\author{
S.M. Marques ${ }^{\mathrm{a}, \mathrm{b}}$, I. Carvalho ${ }^{\mathrm{c}, *}$, M. Henriques ${ }^{\mathrm{b}}$, T. Polcar ${ }^{\mathrm{c}, \mathrm{d}}$, S. Carvalho ${ }^{\mathrm{a}, \mathrm{e}}$ \\ a GRF-CFUM, Physics Department, University of Minho, 4800-058 Guimarães, Portugal \\ b CEB, Centre of Biological Engineering, LIBRO-Laboratório de Investigação em Biofilmes Rosário Oliveira, University of Minho, Campus of Gualtar, $4700-057$ Braga, Portugal \\ c Department of Control Engineering, Faculty of Electrical Engineering, Czech Technical University in Prague, Technická 2, Prague 6, Czech Republic \\ d Engineering Materials, University of Southampton, Highfield, SO17 1BJ Southampton, UK \\ e SEG-CEMUC Mechanical Engineering Department, University of Coimbra, 3030-788 Coimbra, Portugal
}

\section{A R T I C L E I N F O}

Article history:

Received 3 June 2015

Revised 6 September 2015

Accepted in revised form 30 September 2015

Available online 3 October 2015

\section{Keywords:}

Piezoelectric PVDF

Ag coatings

Sputtering

Sensor protection

Antibacterial activity

\begin{abstract}
A B S T R A C T
This work reports on $\mathrm{Ti}_{1}-{ }_{\mathrm{x}} \mathrm{Ag}_{\mathrm{x}}$ and $\mathrm{Ag}-\mathrm{TiN}_{\mathrm{x}}$ electrodes deposited by dc/pulsed dc magnetron sputtering at room temperature on poly (vinylidene fluoride) (PVDF) with the purpose of developing sensors for prosthesis.


tent was varied between 34 and 43 at.\% and the Ti/Ag ratio changed from 12.2 to 5.2. The antibacterial activity of the samples was assessed by the agar diffusion method. Interestingly, samples from the $\mathrm{Ag}-\mathrm{TiN}_{\mathrm{x}}$ series presented antibacterial activity, in contrast to the samples from $\mathrm{Ti}_{1}{ }_{\mathrm{x}} \mathrm{Ag}_{\mathrm{x}}$ series. XPS results showed that the as-deposited samples from the $\mathrm{Ag}_{-} \mathrm{TiN}_{\mathrm{x}}$ series exhibited silver clusters smaller than $4 \mathrm{~nm}$. In order to deepen the results obtained, samples were analysed after the Halo test (antibacterial test), and XPS analyses showed the disappearance of these Ag clusters in agreement with the SEM results, which displayed a visible aggregation and a significant decrease in the number of Ag clusters, suggesting that silver nanoparticles aggregated and diffused through the agar killing bacteria or inhibiting their growth in the vicinity. All results show that $\mathrm{Ag}-\mathrm{TiN}_{\mathrm{x}}$ electrodes are more promising candidates to be used in PVDF sensor protection than $\mathrm{Ti}_{1}{ }_{-} \mathrm{Ag}_{\mathrm{x}}$ electrodes.
\end{abstract}

(c) 2015 Elsevier B.V. All rights reserved.

\section{Introduction}

The use of biomaterials is becoming increasingly common, in most cases as total or partial replacement of organs and tissues. Although there are some biomaterials presenting suitable mechanical properties and low cytotoxicity, they are often prone to microbial colonization [1,2]. This colonization is frequently associated to Staphylococcus epidermidis, being one of the most common bacteria found in orthopaedics prostheses $[3,4]$. In addition, infections caused by this microorganism are often associated to implant failure [5]. Hence, this strengthens the urgent need for the development of new coatings with improved antimicrobial properties.

On the other hand, the future of prosthetic implants lays in the implementation of prevention mechanisms based on sensor systems, which allow to obtain valuable information about a wide range of biomechanical signals [6,7]. Piezoelectric materials are interesting for the development of such sensors because this material transforms mechanical loads into electrical signals, however, conductive electrodes are necessary for signal acquisition. Such electrodes must show good electrical conductivity and, since they are used in the human body, they must be biocompatible. Suitable electrodes may be produced with Ti-based

\footnotetext{
* Corresponding author.

E-mail address: isascarvalho@hotmail.com (I. Carvalho).
}

coatings with multifunctional properties, such as electrical conductivity and antibacterial characteristics. Titanium and its alloys have been widely used as materials for artificial implants due to their biocompatibility and good corrosion resistance [8], and Ti shows electrical conductivity around $43 \mu \Omega \mathrm{cm}[9]$. TiN is an electrically conductive coating, with excellent chemical stability and outstanding mechanical properties, leading to a broad range of applications, including those in the biomedical area $[10,11]$. TiN is also biocompatible, but it is relatively hard [10-13]. The silver addition (good antimicrobial agent) to the TiN films may lead to a softer electrode, since silver presents a low Young's Modulus [21] increasing the plasticity of TiN [11]. So, these surfaces open a wide range of possible applications, especially those related to coatings on polymers to develop flexible devices [10]. As referred above, silver is also known as an antibacterial agent [14-17], in particular in its nanocrystalline form $[13,15]$, and an excellent material for biosensor applications [11]. Akhavan et al. [18,19] reported two studies about the antibacterial effect of silver, one in which an electric field was applied in the direction of silver nanorods grown on a Ti interlayer deposited by dc magnetron sputtering, and another which reported compact Ag nanorods capped by sol-gel mesoporous $\mathrm{TiO}_{2}$ layer, both deposited onto silicon substrates. The two studies showed a strong, fast and lasting antibacterial activity against Escherichia coli (E. coli).

Different coatings produced by magnetron sputtering have been considered as potential candidates for functional conductive electrodes 
for polymeric sensors. Regarding biomedical applications, TiNAg [10,11, $20]$ and TiAg $[9,21]$ coatings have been proposed for prosthesis pressure sensors and dry biopotential electrodes, respectively, due to their specific electrical and biological properties. However, in those studies the coatings were deposited on silicon and glass substrates. In fact, the high temperatures associated with the sputtering process represent the major limitation in the development of functional electrode coatings on piezoelectric PVDF substrates, due to the inevitable structural changes promoted by temperature as well as eventual depolarization of the sample, which leads to the loss of the piezoelectric response. Two recent studies [22,23], show the successful deposition of $\mathrm{Ti}_{1}{ }_{-} \mathrm{Ag}_{\mathrm{x}}$ and $\mathrm{Ag}-\mathrm{TiN}_{\mathrm{x}}$ coatings by sputtering on PVDF substrates, maintaining the piezoelectric response of the polymer.

The aim of the present work is to assess the antibacterial properties of $\mathrm{Ti}_{1}-{ }_{\mathrm{x}} \mathrm{Ag}_{\mathrm{x}}$ and $\mathrm{Ag}-\mathrm{TiN}_{\mathrm{x}}$ electrodes produced by dc magnetron sputtering on PVDF substrate, in order to extend their application potential.

\section{Materials and methods}

\subsection{Coating preparation}

$\mathrm{Ti}_{1}-{ }_{\mathrm{x}} \mathrm{Ag} \mathrm{x}$ and $\mathrm{Ag}-\mathrm{TiN}_{\mathrm{x}}$ coatings were deposited by dc/pulsed dc magnetron sputtering onto PVDF thin films with a thickness of approximately $28 \mu \mathrm{m}$ (Precision Acoustics Ltd.). One pure Ti target (99.99\%) and one $\mathrm{Ag}$ target (99.99\%) (both with $200 \times 100 \mathrm{~mm}^{2}$ ) were used in an argon atmosphere for the $\mathrm{Ti}_{1}{ }_{-} \mathrm{Ag}_{\mathrm{x}}$ coatings and a $\mathrm{Ar}+\mathrm{N}_{2}$ mixture for $\mathrm{Ag}$ - $\mathrm{TiN}_{\mathrm{x}}$ coatings, with the substrates rotating at $70 \mathrm{~mm}$ from the target at a constant speed of $7 \mathrm{rpm}$. For both series, the pressure in the deposition chamber was about $0.17 \mathrm{~Pa}$ and the argon flow was kept constant at $60 \mathrm{sccm}$ while the $\mathrm{N}_{2}$ reactive gas flux was changed in the range of $0-6 \mathrm{sccm}$ for $\mathrm{Ag}-\mathrm{TiN}_{\mathrm{x}}$ coatings. In order not to vary significantly the $\mathrm{Ag}$ content in the $\mathrm{Ag}-\mathrm{TiN}_{\mathrm{x}}$ films, the current density (J) applied to each target was kept constant. The Ti target was connected to the pulsed dc power supply, while the Ag target was connected to a dc power supply. The frequency and reverse time were fixed at $200 \mathrm{kHz}$ and $1536 \mathrm{~ns}$, respectively, corresponding to a duty cycle of $69 \%$. The deposition time was varied in order to obtain a final thickness ranging between 120 to $230 \mathrm{~nm}$. In order to avoid the structural damage of the polymer substrate, the substrate temperature must be ideally kept below $\sim 100{ }^{\circ} \mathrm{C}$, far from the melt transition temperature of PVDF [24]. In this sense, the depositions were performed without any external heating of the substrate and no bias polarization was applied on the substrate holder.

\subsection{Chemical and physical analyses}

Chemical composition was obtained with an EDAX-Pegasus X4MEnergy dispersive spectrometer (EDS/EBSD) apparatus coupled with a scanning electron microscopy (SEM). Since the depth of analysis at $10 \mathrm{kV}$ is about $300 \mathrm{~nm}$ for pure $\mathrm{Ag}$ and $700 \mathrm{~nm}$ for pure titanium, $\mathrm{Ti}_{1}-{ }_{\mathrm{x}} \mathrm{Ag} \mathrm{x}$ and $\mathrm{Ag}-\mathrm{TiN}_{\mathrm{x}}$ coatings with a thickness of $1 \mu \mathrm{m}$ were deposited onto $\mathrm{Si}$ substrate for EDS analysis.

The structure and phase distribution of the coatings were analysed by powder X-ray diffraction (XRD) using a Bruker D8 Discover diffractometer $\left(\mathrm{Cu} \mathrm{K} \alpha\right.$ radiation $-\lambda=1.5406 \AA$, step $0.04^{\circ}$, time per step $1 \mathrm{~s}$ and 6-60 $2 \theta$ interval).

X-ray photoelectron spectroscopy (XPS) was carried out to analyse the chemical bonds of the compounds on the coating surface, before and after biological tests. The XPS analysis was performed using a Kratos AXIS Ultra HSA, with VISION software for data acquisition and CasaXPS software for data analysis. The analysis was carried out with a monochromatic $\mathrm{Al} \mathrm{K \alpha} \mathrm{X}$-ray source (1486.7 eV), operating at $15 \mathrm{kV}(90 \mathrm{~W})$, in FAT mode (Fixed Analyser Transmission), with a pass energy of $40 \mathrm{eV}$ for regions ROI and $80 \mathrm{eV}$ for survey. Data acquisition was performed with a pressure lower than $1 \times 10^{-6} \mathrm{~Pa}$, and a charge neutralization system was used. The effect of the electric charge was corrected by the reference of the carbon peak $(285 \mathrm{eV})$. The deconvolution of spectra was carried out using the CasaXPS programme, in which a peak fitting was performed using Gaussian-Lorentzian peak shape after a Shirley type background subtraction.

The surface morphology was examined by SEM through a NanoSEM-FEI Nova 200 (FEG/SEM) equipped with a field emission gun (FEG), operated in high vacuum mode with a chamber pressure of $0.003 \mathrm{~Pa}$. The micrographs were obtained with secondary (SE) and backscattered (BSE) electron detectors in "through-the-lens" (TLD) mode at acceleration voltage between 5 and $10 \mathrm{kV}$ and working distance of around $5 \mathrm{~mm}$. Measurements were performed in three areas randomly chosen in all samples before and after the biological tests. A magnification of $40000 \times(40 \mathrm{Kx})$ and $150000 \times(150 \mathrm{Kx})$ was used. The particle size and distribution were analysed using the ImageJ software and a descriptive statistical analysis was performed.

\subsection{Antibacterial properties}

The antibacterial activity of $\mathrm{Ti}_{1}{ }_{-} \mathrm{Ag}_{\mathrm{x}}$ and $\mathrm{Ag}-\mathrm{TiN}_{\mathrm{x}}$ coatings was tested against S. epidermidis (IE186 strain, a clinical isolate belonging to the CEB Biofilm Group collection). Zone of inhibition (ZoI) tests, adapted from Kirby-Bauer test [25], were carried out to determine the diffusion of silver from the coating surface. The halo size was used as a qualitative measure of the sample activity.

S. epidermidis was cultivated in liquid medium, by inoculation of a single colony on $20 \mathrm{~mL}$ of Tryptic Soy Broth (TSB, Merck) and incubated for $18 \mathrm{~h}$ at $37^{\circ} \mathrm{C}$ and $120 \mathrm{rpm}$. Afterwards, the resultant cell suspension was adjusted to an optical density (OD) of 1.0 at $640 \mathrm{~nm}$ and properly diluted in TSB to $1 \times 10^{7} \mathrm{CFU} \cdot \mathrm{mL}^{-1}$.

The incubation of the bacteria in the agar was performed in two different ways: in the first one, $1 \mathrm{~mL}$ of cells suspension was added to $14 \mathrm{~mL}$ of cooled $\left(<50{ }^{\circ} \mathrm{C}\right)$ Tryptic Soy Agar (TSA, Merck) and placed into sterile plastic petri dishes; in the second, an aliquot of cell suspension $(100 \mu \mathrm{L})$, containing approximately $1 \times 10^{5} \mathrm{CFU} \cdot \mathrm{mL}^{-1}$ (this concentration is required in order to maintain the same order of magnitude as the first procedure) was spread in TSA petri dishes.

After medium solidification, the samples (previously sterilized by exposure of $\pm 1 \mathrm{~h}$ to UV light) were placed separately on the top of an agar plate, with the coated side in contact with the agar, and incubated for $24 \mathrm{~h}$, at $37^{\circ} \mathrm{C}$. PVDF substrate and Ti and TiN coatings (without silver) were used as negative controls. After the incubation period, the halo (zone of transparent medium, which means that there is no

Table 1

Chemical composition of $\mathrm{Ti}_{1}-{ }_{\mathrm{x}} \mathrm{Ag}_{\mathrm{x}}$ and $\mathrm{Ag}$ - $\mathrm{TiN}_{\mathrm{x}}$ coatings and some experimental details.

\begin{tabular}{|c|c|c|c|c|c|c|c|c|c|c|}
\hline \multirow[t]{2}{*}{ Series } & \multirow[t]{2}{*}{ Coating } & \multirow[t]{2}{*}{$\mathrm{J}_{\mathrm{Ti}}\left(\mathrm{mA} / \mathrm{cm}^{2}\right)$} & \multirow[t]{2}{*}{$\mathrm{J}_{\mathrm{Ag}}\left(\mathrm{mA} / \mathrm{cm}^{2}\right)$} & \multirow[t]{2}{*}{$\mathrm{N}_{2}$ flow $(\mathrm{sccm})$} & \multirow[t]{2}{*}{$\begin{array}{l}\text { Thickness on } \\
\text { polymers (nm) }\end{array}$} & \multirow[t]{2}{*}{$\begin{array}{l}\text { Deposition } \\
\text { rate }(\mathrm{nm} / \mathrm{h})\end{array}$} & \multicolumn{3}{|c|}{$\begin{array}{l}\text { Chemical composition } \\
\text { (at.\%) }\end{array}$} & \multirow[t]{2}{*}{$\mathrm{N} / \mathrm{Ti}$} \\
\hline & & & & & & & $\mathrm{Ti}$ & $\mathrm{Ag}$ & $\mathrm{N}$ & \\
\hline \multirow[t]{3}{*}{$\mathrm{Ti}_{1}-{ }_{\mathrm{x}} \mathrm{Ag} \mathrm{g}_{\mathrm{x}}$ series [22] } & $\mathrm{Ti}$ & 5 & 0 & 0 & 219 & 437 & 100 & 0 & 0 & 0 \\
\hline & $\mathrm{Ag} / \mathrm{Ti}(0.11) \mathrm{R}$ & 7.5 & 0.05 & 0 & 201 & 803 & 93 & 7 & 0 & 0 \\
\hline & $\mathrm{Ag}$ & 0 & 2.5 & 0 & 165 & 659 & 0 & 100 & 0 & 0 \\
\hline \multirow[t]{3}{*}{ Ag-TiN ${ }_{x}$ series } & TiN2AgR & 7.5 & 0.05 & 2 & 227 & 910 & 61 & 5 & 34 & 0.56 \\
\hline & TiN6AgR & 10 & 0.05 & 6 & 129 & 663 & 52 & 10 & 38 & 0.73 \\
\hline & $\mathrm{TiN}$ & 10 & 0 & 6 & 122 & 630 & 57 & 0 & 43 & 0.75 \\
\hline
\end{tabular}




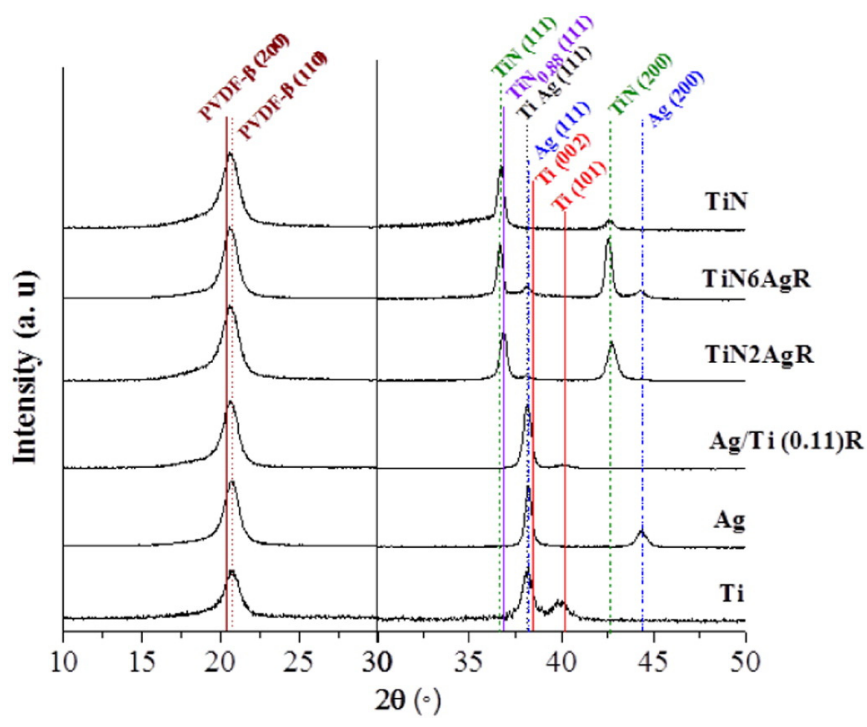

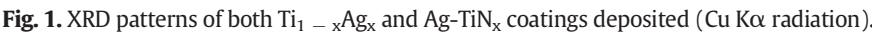

bacteria growth) formed around the sample was measured and photographed to record the results (images captured with Image $\mathrm{Lab}^{\mathrm{TM}}$ software). All experiments were carried out in duplicate per samples and repeated at least in three independent assays.

\section{Results and discussion}

\subsection{Chemical composition}

Table 1 shows some results about deposition conditions, chemical composition together with the thicknesses of the deposited coatings

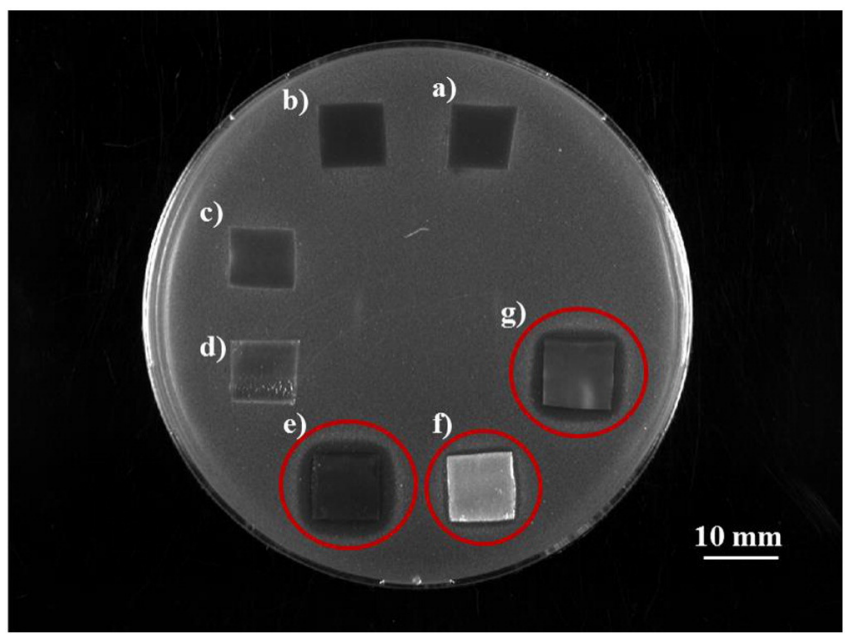

Fig. 3. Antibacterial activity of different samples: a) PVDF, b) TiN, c) Ti, d) Ag/Ti (0.11)R, e) TiN2AgR, f) Ag and g) TiN6AgR against S. epidermidis, evaluated by zone of inhibition assays. The red circles highlight samples with the halo inhibition. (For interpretation of the references to colour in this figure legend, the reader is referred to the web version of this article.)

obtained by SEM analysis. The deposition rate was determined from the deposition time and coating thickness.

The $\mathrm{Ti}_{1}-{ }_{x} \mathrm{Ag}_{\mathrm{x}}$ coatings were labelled according to the $\mathrm{Ag} / \mathrm{Ti}$ atomic ratio, while pure titanium and pure silver coatings are labelled as $\mathrm{Ti}$ and $\mathrm{Ag}$, respectively. The $\mathrm{Ag}-\mathrm{TiN}_{\mathrm{x}}$ series are labelled according to the $\mathrm{N}_{2}$ flow applied e.g. TiN2AgR was deposited with a nitrogen flow of $2 \mathrm{sccm}$ while the titanium nitride is labelled as TiN. Further details concerning the chemical composition versus deposition parameters, of the similar samples, can be found elsewhere [22,23].

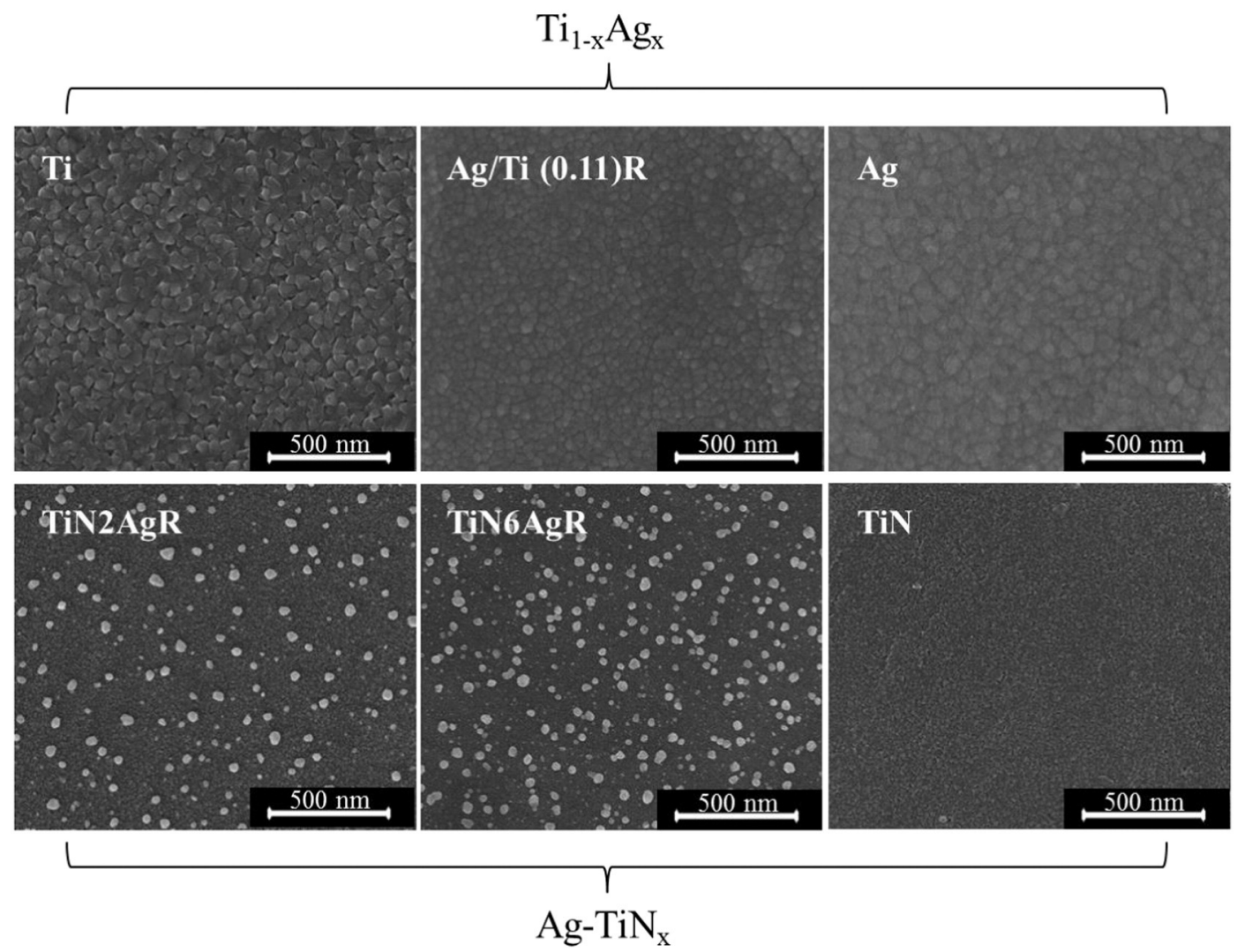

Fig. 2. SEM micrograph of the $\mathrm{Ti}_{1}-{ }_{\mathrm{x}} \mathrm{Ag} \mathrm{g}_{\mathrm{x}}$ and $\mathrm{Ag}-\mathrm{TiN}_{\mathrm{x}}$ coating systems. 


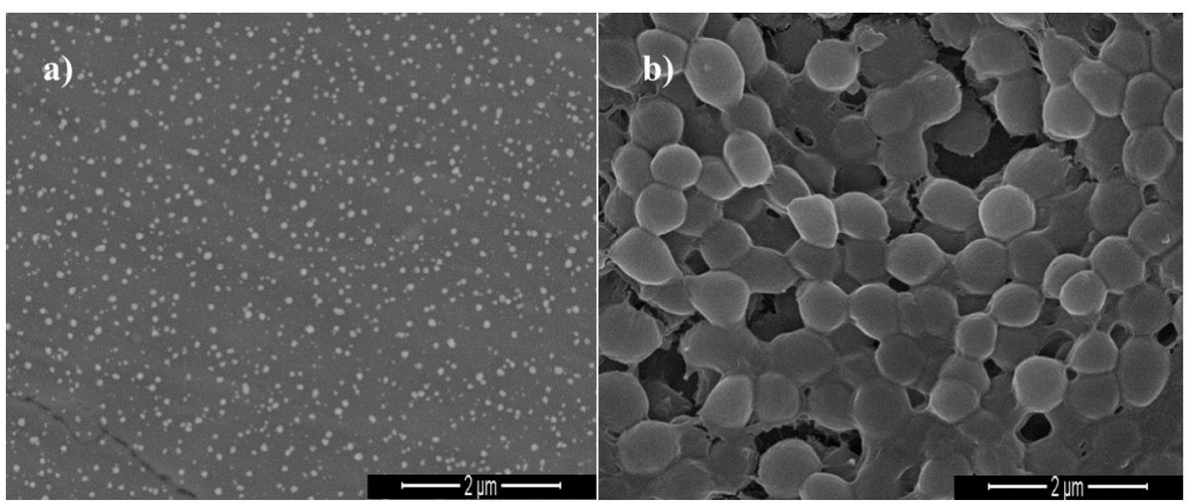

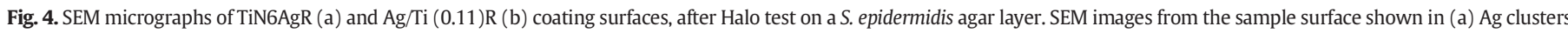
(BSE image) and in (b) microbial colonies.

\subsection{Structural analyses}

Fig. 1 shows the XRD diffraction patterns of $\mathrm{Ti}_{1}{ }_{-\mathrm{x}} \mathrm{Ag} \mathrm{g}_{\mathrm{x}}$ and $\mathrm{Ag}-\mathrm{TiN}_{\mathrm{x}}$ systems. The reference peaks, obtained from the International Centre for Diffraction Data (ICDD) database, of the main crystalline phases are identified namely hexagonal Ti- $\beta$ (ICDD 00-044-1294), fcc-Ag (ICDD 00-004-0783), fcc-TiN (ICDD 00-038-1420) and tetragonal TiAg (ICDD 00-006-0560), together with the crystalline peaks of PVDF (ICDD 00-042-1649) [24].

XRD peaks corresponding to atomic planes (200) and (110) of $\beta$ PVDF (Fig. 1a) indicate that the deposition conditions do not induce any phase change in the polymer. This means that the piezoelectric phase of PVDF is still present. These results were in fact already discussed in previous works reported by the authors [22,23]. The published results stated that for $\mathrm{Ti}_{1}{ }_{\mathrm{x}} \mathrm{Ag}_{\mathrm{x}}$ series, the values of the piezoelectric response vary from 19.6 to $27.6 \mathrm{pC} \mathrm{N}^{-1}$, allow maintaining the functional piezoelectric response of the polymer.
For the TiN-Ag series, with increasing nitrogen flow, the piezoelectricity response tends to decrease. However, this slight variation does not compromise the piezoelectric response for the required application. Further discussion and details can be seen elsewhere [22,23]. The XRD pattern of $\mathrm{Ag} / \mathrm{Ti}(0.11) \mathrm{R}$ coating indicates that the most intense peak is located at $\sim 38.1^{\circ}$, which is very close to the TiAg (111) and Ag (111) peaks (see Fig. 1b). Previous studies of TiAg coatings deposited by magnetron sputtering suggested the formation of the TiAg crystalline phase, although it is difficult to identify Ag, Ti- $\beta$ and TiAg phases since they show very similar diffraction patterns $[9,22,23]$. Together with the TiAg phase, the presence of the $\mathrm{Ti}$ (002) peak can also be identified, which suggests that the coating is composed by a mixture of crystalline TiAg and Ti phases. Since the amount of Ti present in the coating is high (93 at.\%), TiAg phase is formed until the $\mathrm{Ag}$ is consumed and the remaining titanium forms a crystalline Ti phase $[22,23]$.

TiN6AgR and TiN coatings display a diffraction peak located at $\sim 36.7$ which is attributed to fcc-TiN phase and TiN2AgR coating exhibits a

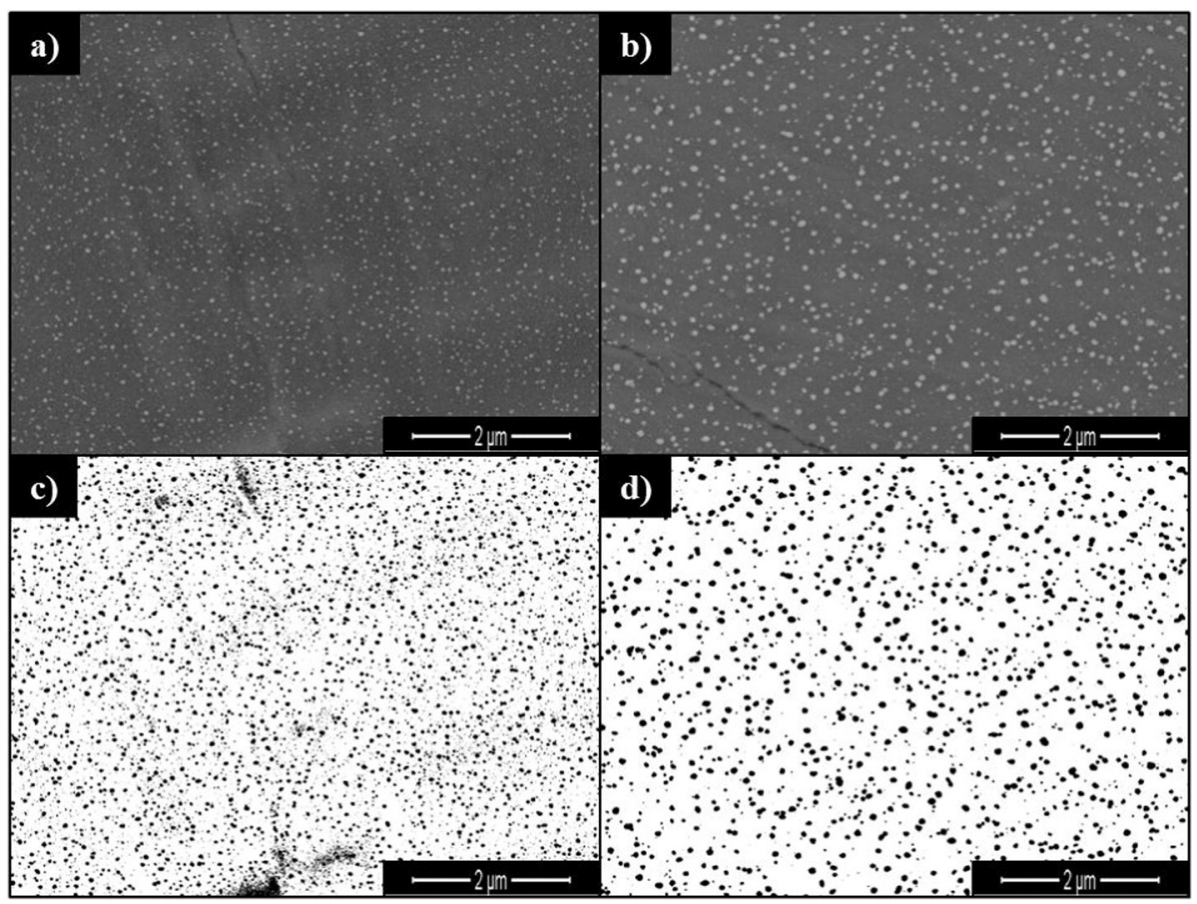

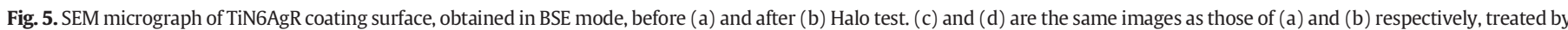
ImageJ software. 
diffraction peak at $\sim 36.9^{\circ}$ ascribed to sub-stoichiometric TiN phase that can be related to lower N/Ti atomic ratio in this film than in the standards. These samples show another peak located at $\sim 42.5^{\circ}$ which has been assigned to TiN (200). A previous study with similar coatings also detected such peak; however, it was observed in coatings with higher Ag contents [10]. To minimize the surface energy, the atoms tend to have plans with the maximum compactness parallel to the surface, in the case of fcc-phase the plan is 111 but due to the new phase growth (Ag phase), these conditions can be changed. Furthermore, this new phase is detected in samples with silver (TiN2AgR and TiN6AgR) showing two diffraction peaks at $\sim 38^{\circ}$ and $\sim 44.4^{\circ}$ which represent (111) and (200) planes of fcc-Ag, respectively.

\subsection{Morphology}

SEM analyses were performed in order to evaluate surface characteristics of the films, such as the presence of Ag clusters on the surface before and after biological tests. Fig. 2 show the SEM micrograph of the coatings of both $\mathrm{Ti}_{1}-{ }_{\mathrm{x}} \mathrm{Ag} \mathrm{g}_{\mathrm{x}}$ and $\mathrm{Ag}-\mathrm{TiN}_{\mathrm{x}}$ systems, before the Halo test.

The SEM micrographs of similar coatings of $\mathrm{Ti}_{1}{ }_{-}{ }_{\mathrm{x}} \mathrm{Ag}_{\mathrm{x}}$ systems were discussed in a previous paper [22], where it was verified that the coatings were homogeneous and no clusters were found on the surface. The present films also do not show any Ag clusters, which corroborates the XRD analysis (Fig. 1), suggesting the formation of crystalline TiAg phases. On the other hand, the surface of the $\mathrm{Ag}-\mathrm{TiN}_{\mathrm{x}}$ coating system exhibited $\mathrm{Ag}$ clusters like what the authors discussed in a previous paper [23]. Several studies reported that the co-deposition of Ag and titanium nitride ( $\mathrm{TiN})$ [26], carbonitride ( $\mathrm{TiCN})$ [27] and oxide $\left(\mathrm{TiO}_{2}\right)$ [28] results in the formation of nanocomposites with $\mathrm{Ag}$ nanoparticles embedded in the matrix coating, and the size of these nanoparticles strongly depends on the amount of silver incorporated in the coating. The formation of $\mathrm{Ag}$ nanoparticles is related to the immiscibility of $\mathrm{Ag}$ in these matrices. Lopes et al. [9] and also the authors [23] reported that $\mathrm{Ag}-\mathrm{TiN}_{\mathrm{x}}$ coatings were composed by Ag clusters segregated from the TiN cubic grain boundaries.

\subsection{Antibacterial properties}

Fig. 3 shows an example of the Halo tests carried out on $\mathrm{Ti}_{1}-{ }_{\mathrm{x}} \mathrm{Ag}_{\mathrm{x}}$, $\mathrm{Ag}-\mathrm{TiN}_{\mathrm{x}}$ systems and PVDF substrate. Fig. 3a depicts the PVDF substrate, and Fig. 3c, d and f shows $\mathrm{Ti}, \mathrm{Ag} / \mathrm{Ti}(0.11) \mathrm{R}$ and $\mathrm{Ag}$ samples from $\mathrm{Ti}_{1}{ }_{\mathrm{x}} \mathrm{Ag}_{\mathrm{x}}$ system, respectively. Fig. 3b, e and $\mathrm{g}$ displays respectively TiN, TiN2AgR and TiN6AgR samples from Ag-TiNx system. The Ag coating (Fig. 3f) shows a weak halo around $(\sim 0.5 \pm 0.08 \mathrm{~mm})$, which maybe is too small to attest antibacterial properties. In contrast, in samples with Ag from the Ag-TiNx system (TiN2AgR and TiN6AgR - Fig. 3e and $g$, respectively), it is possible to observe a clear halo surrounding the samples with silver, with dimensions between $\sim 1.8 \pm 0.3 \mathrm{~mm}$ and $\sim 1.4 \pm 0.1 \mathrm{~mm}$ for TiN2AgR and TiN6AgR respectively, enhancing the antibacterial activity. This result is ascribed to the silver diffusion through the agar.

Interestingly, in spite of the fact that $\mathrm{Ag} / \mathrm{Ti}$ (0.11)R sample (Fig. 3d) possesses silver in its composition, it does not have any inhibition zone. This apparent absence of antibacterial activity may be explained by the bonding between $\mathrm{Ag}$ and Ti preventing silver segregation and hence its diffusion (the chemical bonds will be discussed later in Section 3.5). This assumption is consistent with previous XRD results, which showed the possible formation of crystalline TiAg phases.

Fig. 4 presents the SEM images of coating surface, after microbiological tests from TiN6AgR and $\mathrm{Ag} / \mathrm{Ti}(0.11) \mathrm{R}$ samples of $\mathrm{Ag}-\mathrm{TiN}_{\mathrm{x}}$ and $\mathrm{Ti}_{1}-{ }_{\mathrm{x}} \mathrm{Ag} \mathrm{g}_{\mathrm{x}}$ systems, respectively. It should be noted that SEM analysis was performed on all samples, however only one sample from each series is presented, samples TiN6AgR and $\mathrm{Ag} / \mathrm{Ti}(0.11) \mathrm{R}$; despite having similar amounts of silver, the matrices are completely different, so it is
Table 2

Percentage of Ag area covered and number of $\mathrm{Ag}$ particles in the TiN6AgR sample surface.

\begin{tabular}{lll}
\hline TiN6AgR & Ag area (\%) & Number of particles \\
\hline As deposited & 14 & 9012 \\
After Halo test & 8 & 1517 \\
\hline
\end{tabular}

expected that silver has different behaviours. Because of that, these two samples were chosen as representative for each series.

From the observation of the surface of samples from the $\mathrm{Ag}^{-\mathrm{TiN}_{\mathrm{x}}}$ system (Fig. 4a), no bacteria on the surface are noticed, corroborating its antibacterial effect observed in the Halo test (Fig. 3). Fig. 4a was obtained using the BSE mode and clearly shows Ag clusters dispersed all over the film surface. $\mathrm{Ag} / \mathrm{Ti}(0.11) \mathrm{R}$ coating (Fig. $4 \mathrm{~b}$ ) of $\mathrm{Ti}_{1}{ }_{-} \mathrm{Ag}_{\mathrm{x}}$ systems shows some microbial colonies. These results confirm that silver in the $\mathrm{Ti}_{1}-{ }_{\mathrm{x}} \mathrm{Ag}_{\mathrm{x}}$ coating system has no antibacterial effect, allowing bacterial colonization, in contrast with the antibacterial activity of the Ag-TiN coating system, which presents a reduction in the number Ag nanoparticles at the surface after biological test (discussed below) certainly due to their diffusion through the agar which induce inhibition of bacteria growth.

Fig. 5 shows the TiN6AgR coating surface before (a) and after (b) the Halo test. Fig. $5 c$ and d corresponds to Fig. $5 \mathrm{a}$ and b, respectively, treated by ImageJ software. The SEM micrographs clearly show a modification on coating's surface after the Halo test, where it is possible to observe: i) an increase in the $\mathrm{Ag}$ particle size and ii) a decrease in the number of $\mathrm{Ag}$ nanoparticles. In order to quantify this trends, i) the covering area of the particles in relation to the total area was calculated and reported as a percentage and ii) the number of particles (independently of the size) was counted being the results shown in Table 2 . In addition, the corresponding particle size distribution histograms of the silver particles before and after the Halo test are shown in Fig. 6. After the Halo test, there is a $6 \%$ reduction in the area occupied by the $\mathrm{Ag}$ nanoparticles, which is accompanied by a reduction in the total number of Ag particles. Simultaneously the histograms clearly suggest an increase in the particle size. Thus, it might be concluded that during the Halo tests a phenomenon of particle agglomeration or coalescence is occurring, which might be combined with some diffusion of Ag through the agar, which probably contributes to the reduction in the number of $\mathrm{Ag}$ particles. The Ag nanoparticle agglomeration in different fluids has been reported by Li et al. [29] and this agglomeration was attributed to the occurrence of Ag dissolution. In fact, dissolution-precipitation is a well-established coalescence process that occurs in liquid media. This process is also known as Ostwald ripening and it involves the dissolution (in this case ionization of $\mathrm{Ag}$ ) of small $\mathrm{Ag}$ nanoparticles, which aftermost grow

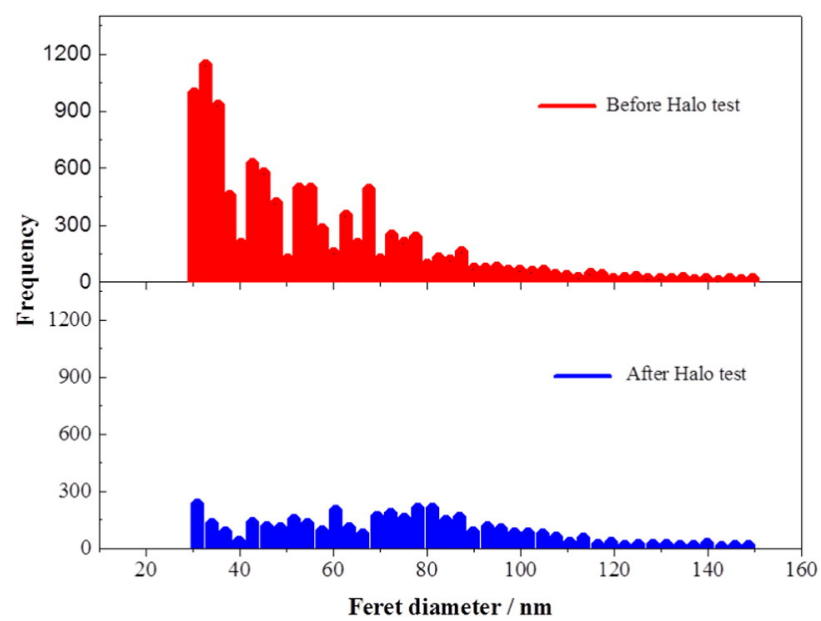

Fig. 6. Particle size distribution histogram of the silver nanoparticles, evaluated from the corresponding SEM micrograph of TiN6AgR coating surface. 
a)

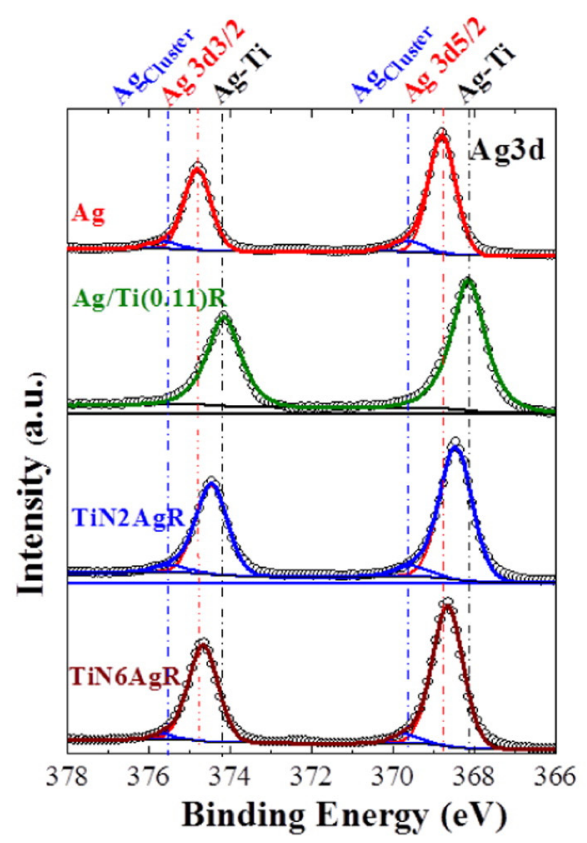

b)

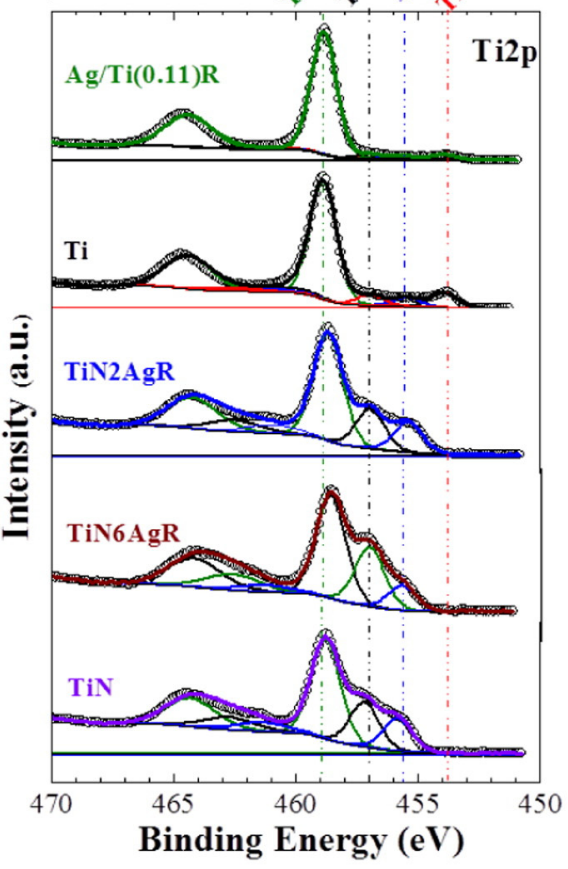

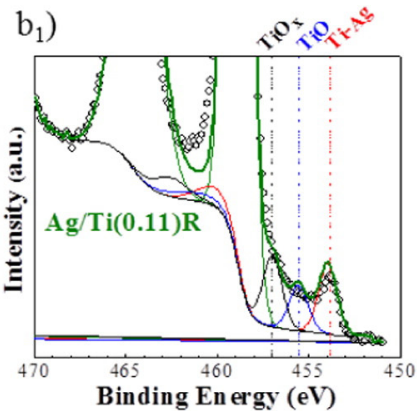

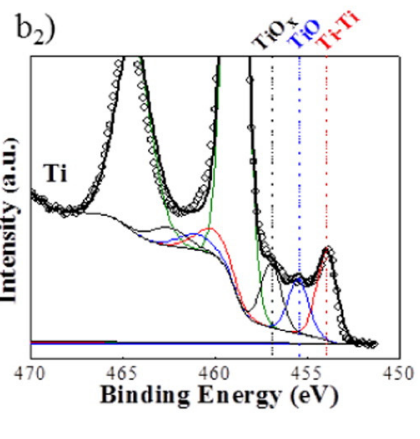

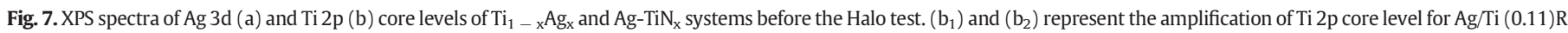
and Ti coatings, respectively.

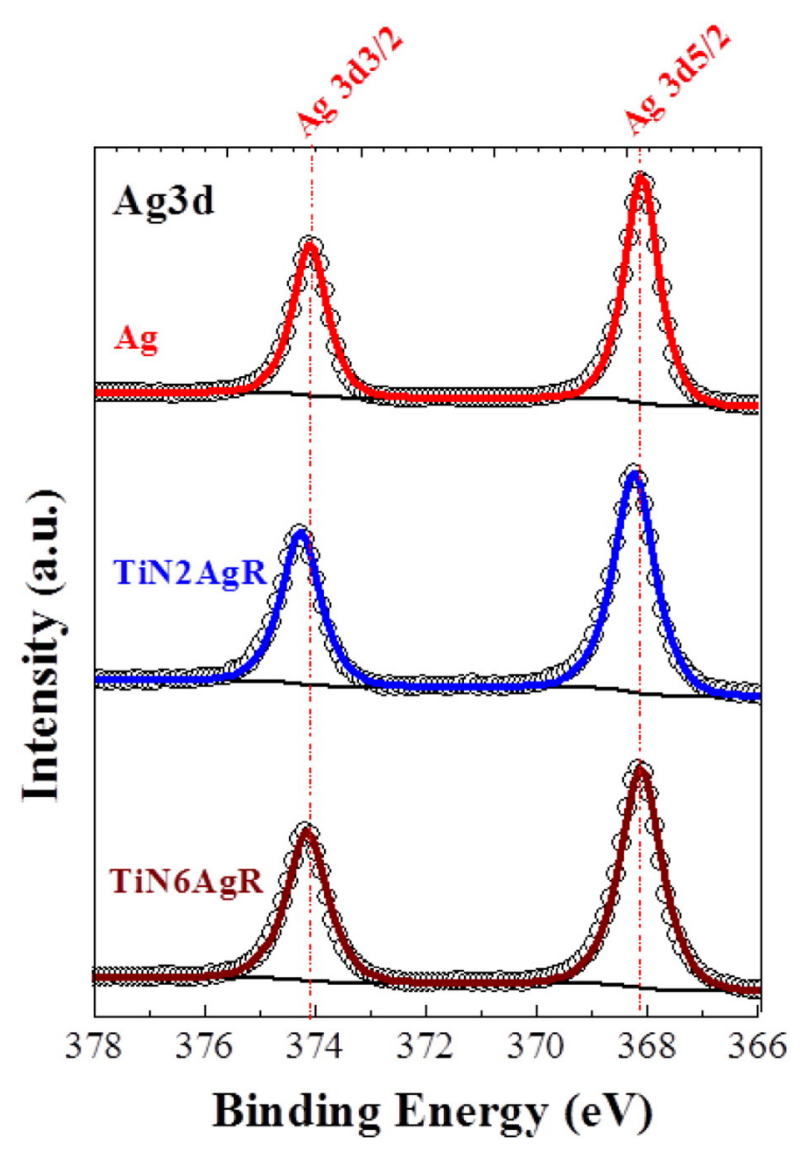

Fig. 8. XPS spectra of $\mathrm{Ag} 3 \mathrm{~d}$ core level of $\mathrm{Ti}_{1}{ }_{-} \mathrm{Ag}_{\mathrm{x}}$ and $\mathrm{Ag}$-TiN $\mathrm{x}_{\mathrm{x}}$ systems after the Halo test. on the surface of bigger Ag nanoparticles [30]. Possibly, this mechanism explains the increase in Ag particle size during the Halo test, and it plays a fundamental role in the antibacterial performance, since it is accepted that the $\mathrm{Ag}$ biocidal activity is mostly promoted by the presence of $\mathrm{Ag}$ ions.

Other studies assessed the release behaviour of silver ions of composites as $\mathrm{Ag} / \mathrm{TiO}_{2}, \mathrm{Ag}-\mathrm{SiO}_{2}$, and attributed to water diffusion characteristics on the matrix [31,32].

\subsection{Chemical bonding analysis by XPS}

XPS analyses were performed on as deposited samples of both $\mathrm{Ti}_{1}-{ }_{\mathrm{x}} \mathrm{Ag}_{\mathrm{x}}$ and $\mathrm{Ag}-\mathrm{TiN}_{\mathrm{x}}$ systems and on samples with antibacterial activity after performing the Halo test in order to relate the chemical changes in the sample surface.

Fig. 7a shows the Ag 3d photoelectron spectra of $\mathrm{Ag}, \mathrm{Ag} / \mathrm{Ti}(0.11) \mathrm{R}$, TiN2AgR and TiN6AgR coatings before performing the Halo test. The $\mathrm{Ag} / \mathrm{Ti}(0.11) \mathrm{R}$ coating shows an $\mathrm{Ag} 3 \mathrm{~d}$ doublet with the $\mathrm{Ag} 3 \mathrm{~d}_{5 / 2}$ peak at $\sim 368.1 \mathrm{eV}$ (separated of $\mathrm{Ag} 3 \mathrm{~d}_{3 / 2}$ peak by $6.0 \mathrm{eV}$ ) with full width at half maximum (FWHM) of $\sim 1.0 \mathrm{eV}$ which is attributed to $\mathrm{Ag}-\mathrm{Ti}$ bond, in accordance with Moulder et al. [33] which identified this bond as $\mathrm{Ag}$ alloys. The counterpart is also observed in Fig. $7 \mathrm{~b}$ in the Ti $2 \mathrm{p}_{3 / 2}$ band at $\sim 453.9 \mathrm{eV}$ (separated of Ti $2 \mathrm{p}_{1 / 2}$ by $\sim 6.2 \mathrm{eV}$ ) with FWHM of $\sim 1.2 \mathrm{eV}$ which is assigned to $\mathrm{Ag}-\mathrm{Ti}$ and Ti-Ti bonds for $\mathrm{Ag} / \mathrm{Ti}(0.11) \mathrm{R}$ and Ti coating, respectively. These bands can be observed in the amplified Fig. 7b1 and b2. These results corroborate the resistivity results for $\mathrm{Ti}_{1}-{ }_{\mathrm{x}} \mathrm{Ag}_{\mathrm{x}}$ series, showing a typical behaviour of a binary alloy system, already published by the authors in another paper [22], and confirm the aforementioned antibacterial inactivity since silver is not available to diffuse through the agar. Ag, TiN2AgR and TiN6AgR coatings show the deconvolution of $\mathrm{Ag}$ 3d doublet into two Gaussian components (each Gaussian component of $\mathrm{Ag} 3 \mathrm{~d}_{5 / 2}$ and $\mathrm{Ag} 3 \mathrm{~d}_{3 / 2}$ separated by $6.0 \mathrm{eV}$ ). The binding energy of the one of $\mathrm{Ag} 3 \mathrm{~d}_{5 / 2}$ peak component is 
$\sim 368.8 \mathrm{eV}$ with FWHM of $\sim 0.9 \mathrm{eV}$ which is attributed to $\mathrm{Ag}-\mathrm{Ag}$ metallic bonds [25]. The binding energy of the other component appears approximately to $369.5 \mathrm{eV}(\sim 1.1 \mathrm{eV}$ FWHM), which is ascribed to metallic sub-nanoparticles associated with clusters smaller than $4 \mathrm{~nm}$ [34]. Calderon et al. [35] had also detected this band in $\mathrm{ZrCN}-\mathrm{Ag}$ samples. After performing the Halo test, this contribution (metallic subnanoparticles) disappears as observed in Fig. 8. These outcomes are in agreement with the SEM results that showed the existence of such nanoparticles on TiN2AgR and TiN6AgR coating surface before the biological tests, whereas a perceptible aggregation (increase on the particle size) and a significant decrease in cluster number (small particles) are observed after the biological tests.

\section{Conclusion}

The aim of this study was the evaluation of the antibacterial properties of $\mathrm{TiN}_{\mathrm{x}}-{ }_{1} \mathrm{Ag}_{\mathrm{x}}$ and $\mathrm{Ag}-\mathrm{TiN}_{\mathrm{x}}$ systems. In both systems, it was observed the presence of $\beta$-PVDF phase diffraction peaks, which indicate that the deposition conditions did not damage the polymeric substrate, being possible to conclude that piezoelectric properties were kept. This is useful for the development of sensors for biomedical application. In this sense it is essential to establish whether the materials show antibacterial properties.

It has been demonstrated that only the $\mathrm{Ag}$ - $\mathrm{TiN}_{\mathrm{x}}$ coatings show antibacterial activity. In this case, $\mathrm{Ag}$ clusters are formed on the coating surface and silver can diffuse through the agar inducing inhibition of bacterial growth. In the case of $\mathrm{Ti}_{1}-{ }_{\mathrm{x}} \mathrm{Ag}_{\mathrm{x}}$ system, silver is chemically bonded ( $\mathrm{Ti}-\mathrm{Ag}$ bond) so, it does not show any antibacterial activity. Although pure Ag coating produces a halo during bacterial tests, the ZoI measure is too small to conclude whether this coating has antibacterial properties.

Further studies should be carried out in order to clarify the effect of silver and/or silver ion release.

This work highlighted the potential of silver nanoparticles, especially in the $\mathrm{Ag}_{-} \mathrm{TiN}_{\mathrm{x}}$ series, and it was an essential step towards the assessment of the ideal system for used as sensor protection.

\section{Acknowledgements}

S. M. Marques gratefully acknowledges the funding from the Portuguese National funds through the FCT - Fundação para a Ciência e a Tecnologia, (project SFRH/BD/71259/2010). Also, the authors thank the support of FEDER through the COMPETE Programme and of the Portuguese Foundation for Science and Technology (FCT) in the framework of the Strategic Project PEST-C/FIS/UI607/2014 and the project Matepro-Optimizing Materials and Processes, ref. NORTE-07-0124FEDER-000037", co-funded by the "Programa Operacional Regional do Norte" (ON.2 - O Novo Norte), under the "Quadro de Referência Estratégico Nacional" (QREN), through the "Fundo Europeu de Desenvolvimento Regional" (FEDER).

The authors thank the FCT Strategic Project of UID/BIO/04469/2013 unit, the project RECI/BBB-EBI/0179/2012 (FCOMP-01-0124-FEDER027462) and the project "Biolnd - Biotechnology and Bioengineering for improved Industrial and Agro-Food processes", REF. NORTE-070124-FEDER-000028 co-funded by the Programa Operacional Regional do Norte (ON.2 - O Novo Norte), QREN, FEDER.

The authors thank the FCT Strategic Project of UID/BIO/04469/2013 unit, the project RECI/BBB-EBI/0179/2012 (FCOMP-01-0124-FEDER027462) and the Project "BioHealth - Biotechnology and Bioengineering approaches to improve health quality”, Ref. NORTE-07-0124FEDER-000027, co-funded by the Programa Operacional Regional do Norte (ON.2 - O Novo Norte), QREN, FEDER.

The authors thank the FCT Strategic Project of UID/BIO/04469/ 2013 unit, the project RECI/BBB-EBI/0179/2012 (FCOMP-01-0124FEDER-027462) and the Project "BioEnv - Biotechnology and Bioengineering for a sustainable world”, REF. NORTE-07-0124-FEDER-000048, co-funded by the Programa Operacional Regional do Norte (ON.2 - O Novo Norte), QREN, FEDER.

This work has been done with the support of inter-sectoral mobility and quality enhancement of research teams at Czech Technical University in Prague, CZ.1.07/2.3.00/30.0034.

\section{References}

[1] F. Guimarães, C. Oliveira, E. Sequeiros, M. Torres, M. Susano, Structural and mechanical properties of Ti-Si-C-ON for biomedical applications, Technology 202 (2008) 2403-2407, http://dx.doi.org/10.1016/j.surfcoat.2007.08.056.

[2] C. Oliveira, L. Gonçalves, B.G. Almeida, C.J. Tavares, S. Carvalho, F. Vaz, et al., XRD and FTIR analysis of Ti-Si-C-ON coatings for biomedical applications, Surf. Coat. Technol. 203 (2008) 490-494, http://dx.doi.org/10.1016/j.surfcoat.2008.06.121.

[3] L. Montanaro, P. Speziale, D. Campoccia, S. Ravaioli, I. Cangini, G. Pietrocola, et al., Scenery of Staphylococcus implant infections in orthopedics, Future Microbiol. 6 (2011) 1329-1349, http://dx.doi.org/10.2217/fmb.11.117.

[4] J.P. O'Gara, H. Humphreys, Staphylococcus epidermidis biofilms: importance and implications, J. Med. Microbiol. 50 (2001) 582-587 (http://www.ncbi.nlm.nih.gov/ pubmed/11444767).

[5] P.F. Sharkey, W.J. Hozack, R.H. Rothman, S. Shastri, S.M. Jacoby, Insall award paper. Why are total knee arthroplasties failing today? Clin. Orthop. Relat. Res. 7-13 (2002) (http://www.ncbi.nlm.nih.gov/pubmed/12439231 (accessed May 30, 2014)).

[6] R. Brånemark, P.I. Brånemark, B. Rydevik, R.R. Myers, Osseointegration in skeletal reconstruction and rehabilitation: a review, J. Rehabil. Res. Dev. 38 (2001) 175-181.

[7] S.P. Mohanty, E. Kougianos, Biosensors: A Tutorial Review, (n.d.) 1-12.

[8] C.F.A. Alves, F. Oliveira, I. Carvalho, A.P. Piedade, S. Carvalho, Influence of albumin on the tribological behavior of $\mathrm{Ag}-\mathrm{Ti}(\mathrm{C}, \mathrm{N})$ thin films for orthopedic implants, Mater. Sci. Eng. C Mater. Biol. Appl. 34 (2014) 22-28, http://dx.doi.org/10.1016/j.msec. 2013.09.031.

[9] C. Lopes, C. Gonçalves, P. Pedrosa, F. Macedo, E. Alves, N.P. Barradas, et al., TiAgx thin films for lower limb prosthesis pressure sensors: effect of composition and structural changes on the electrical and thermal response of the films, Appl. Surf. Sci. 285 (2013) 10-18, http://dx.doi.org/10.1016/j.apsusc.2013.07.021.

[10] P. Pedrosa, D. Machado, C. Lopes, E. Alves, N.P. Barradas, N. Martin, et al., Applied Surface Science Nanocomposite Ag:TiN thin films for dry biopotential electrodes, Appl. Surf. Sci. 285 (2013) 40-48, http://dx.doi.org/10.1016/j.apsusc.2013.07.154.

[11] P. Pedrosa, E. Alves, N.P. Barradas, N. Martin, P. Fiedler, J. Haueisen, et al., Electrochemical behaviour of nanocomposite Agx:TiN thin films for dry biopotential electrodes, Electrochim. Acta 125 (2014) 48-57, http://dx.doi.org/10.1016/j.electacta. 2014.01.082.

[12] S. Piscanec, L. Colombi, E. Vesselli, G. Comelli, O. Sbaizero, S. Meriani, et al., Bioactivity of TiN-coated titanium implants, Acta Mater. 52 (2004) 1237-1245, http://dx.doi. org/10.1016/j.actamat.2003.11.020.

[13] P.J.J. Kelly, H. Li, P.S.S. Benson, K.A.A. Whitehead, J. Verran, R.D.D. Arnell, et al., Comparison of the tribological and antimicrobial properties of $\mathrm{CrN} / \mathrm{Ag}, \mathrm{ZrN} / \mathrm{Ag}$, TiN/Ag, and TiN/Cu nanocomposite coatings, Surf. Coat. Technol. 205 (2010) 1606-1610, http://dx.doi.org/10.1016/j.surfcoat.2010.07.029.

[14] H. Cao, X. Liu, F. Meng, P.K. Chu, Biological actions of silver nanoparticles embedded in titanium controlled by micro-galvanic effects, Biomaterials 32 (2011) 693-705, http://dx.doi.org/10.1016/j.biomaterials.2010.09.066.

[15] P.J.J. Kelly, H. Li, K.A.A. Whitehead, J. Verran, R.D.D. Arnell, I. Iordanova, A study of the antimicrobial and tribological properties of TiN/Ag nanocomposite coatings, Surf. Coat. Technol. 204 (2009) 1137-1140, http://dx.doi.org/10.1016/j.surfcoat.2009. 05.012 .

[16] D.R. Monteiro, L.F. Gorup, A.S. Takamiya, A.C. Ruvollo-Filho, E.R. de Camargo, D.B. Barbosa, The growing importance of materials that prevent microbial adhesion: antimicrobial effect of medical devices containing silver, Int. J. Antimicrob. Agents 34 (2009) 103-110, http://dx.doi.org/10.1016/j.jjantimicag.2009.01.017.

[17] M. Rai, A. Yadav, A. Gade, Silver nanoparticles as a new generation of antimicrobials, Biotechnol. Adv. 27 (2009) 76-83, http://dx.doi.org/10.1016/j.biotechadv.2008.09.002.

[18] O. Akhavan, E. Ghaderi, Capping antibacterial Ag nanorods aligned on Ti interlayer by mesoporous $\mathrm{TiO}_{2}$ layer, Surf. Coat. Technol. 203 (2009) 3123-3128, http://dx. doi.org/10.1016/j.surfcoat.2009.03.033.

[19] O. Akhavan, E. Ghaderi, Enhancement of antibacterial properties of Ag nanorods by electric field, Sci. Technol. Adv. Mater. 10 (2009) 015003, http://dx.doi.org/10.1088/ 1468-6996/10/1/015003.

[20] P. Pedrosa, C. Lopes, N. Martin, C. Fonseca, F. Vaz, Electrical characterization of Ag: TiN thin films produced by glancing angle deposition, Mater. Lett. 115 (2014) 136-139, http://dx.doi.org/10.1016/j.matlet.2013.10.044.

[21] D. Machado, P. Pedrosa, C. Fonseca, N. Martin, F. Vaz, Structural and morphological changes in $\mathrm{Ag}$ :TiN nanocomposite films promoted by in-vacuum annealing, J. Nano Res. 25 (2013) 67-76, http://dx.doi.org/10.4028/www.scientific.net/JNanoR. 25.67.

[22] S.M. Marques, N.K. Manninen, S. Ferdov, S. Lanceros-Mendez, S. Carvalho, Ti1 - xAgx electrodes deposited on polymer based sensors, Appl. Surf. Sci. 317 (2014) 490-495, http://dx.doi.org/10.1016/j.apsusc.2014.08.142.

[23] S.M. Marques, N.K. Manninen, S. Lanceros-Mendez, S. Carvalho, Ag-TiNx electrodes deposited on piezoelectric poly(vinylidene fluoride) for biomedical sensor applications, Sensors Actuators A Phys. (2015)http://dx.doi.org/10.1016/j.sna.2015.08.016.

[24] P. Martins, A.C.C. Lopes, S. Lanceros-Mendez, Electroactive phases of poly(vinylidene fluoride): determination, processing and applications, Prog. Polym. Sci. 39 (2014) 683-706, http://dx.doi.org/10.1016/j.progpolymsci.2013.07.006. 
[25] A. Bauer, W. Kirby, J. Sherris, M. Turk, Antibiotic susceptibility testing by standard single disk method, Am. J. Clin. Pathol. 45 (1966) 493-496.

[26] T. de los Arcos, P. Oelhafen, U. Aebi, A. Hefti, M. Düggelin, D. Mathys, et al., Preparation and characterization of TiN-Ag nanocomposite films, Vacuum 67 (2002) 463-470, http://dx.doi.org/10.1016/S0042-207X(02)00232-4.

[27] R. Escobar Galindo, N.K. Manninen, C. Palacio, S. Carvalho, Advanced surface characterization of silver nanocluster segregation in Ag-TiCN bioactive coatings by RBS, GDOES, and ARXPS, Anal. Bioanal. Chem. 405 (2013) 6259-6269, http://dx.doi. org/10.1007/s00216-013-7058-z.

[28] V.S.K. Chakravadhanula, T. Hrkac, V. Zaporojtchenko, R. Podschun, V.G. Kotnur, A. Kulkarni, et al., Nanostructural and functional properties of $\mathrm{Ag}-\mathrm{TiO}_{2}$ coatings prepared by co-sputtering deposition technique, J. Nanosci. Nanotechnol. 11 (2011) 4893-4899, http://dx.doi.org/10.1140/epjd/e2007-00186-5.

[29] X. Li, J.J. Lenhart, H.W. Walker, Dissolution-accompanied aggregation kinetics of silver nanoparticles, Langmuir 26 (2010) 16690-16698, http://dx.doi.org/10.1021 la101768n.

[30] G. Cao, Nanostructures and Nanomaterials - Synthesis, Properties and Applications, Imperial College Press, London, 2004http://dx.doi.org/10.1142/9781860945960.
[31] Y. Liu, X. Wang, F. Yang, X. Yang, Excellent antimicrobial properties of mesoporous anatase $\mathrm{TiO}_{2}$ and $\mathrm{Ag} / \mathrm{TiO}_{2}$ composite films, Microporous Mesoporous Mater. 114 (2008) 431-439, http://dx.doi.org/10.1016/j.micromeso.2008.01.032.

[32] O. Akhavan, E. Ghaderi, Bactericidal effects of Ag nanoparticles immobilized on surface of $\mathrm{SiO}_{2}$ thin film with high concentration, Curr. Appl. Phys. 9 (2009) 1381-1385, http://dx.doi.org/10.1016/j.cap.2009.03.003.

[33] J.F. Moulder, W.F. Stickle, P.E. Sobol, K.D. Bomben, Handbook of X-ray Photoelectron Spectroscopy, Perkin-Elmer Corporation, 1979http://dx.doi.org/10.1002 sia.740030412.

[34] A. Siozios, H. Zoubos, N. Pliatsikas, D.C. Koutsogeorgis, G. Vourlias, E. Pavlidou, et al., Growth and annealing strategies to control the microstructure of AIN:Ag nanocomposite films for plasmonic applications, Surf. Coat. Technol. 255 (2014) 28-36, http://dx.doi.org/10.1016/j.surfcoat.2013.11.025.

[35] S.C. Velasco, V. Lopez, C.F.A. Alves, a. Cavaleiro, S. Carvalho, Structural and electrochemical characterization of $\mathrm{Zr}-\mathrm{C}-\mathrm{N}-\mathrm{Ag}$ coatings deposited by DC dual magnetron sputtering, Corros. Sci. 80 (2014) 229-236, http://dx.doi.org/10.1016/j.corsci.2013. 11.036. 